\title{
Iron deficiency screening for children at 18 months: a cost-utility analysis
}

\author{
Sarah Carsley PhD, Rui Fu MSc, Cornelia M. Borkhoff PhD, Nadine Reid PhD, Eva Baginska MBA, \\ Catherine S. Birken MD MSc, Jonathon L. Maguire MD MSc, Rebecca Hancock-Howard PhD, \\ Patricia C. Parkin MD, Peter C. Coyte $\mathrm{PhD}$
}

Abstract

Background: The peak prevalence of iron deficiency is in children 6 months to 3 years of age, a sensitive period for neurodevelopment. Our study objective was to examine the cost-utility of a proposed iron deficiency screening program for 18-month-old children.

Methods: We used a decision tree model to estimate the costs in 2019 Canadian dollars and quality-adjusted life years (QALYs) associated with 3 iron deficiency screening strategies: no screening, universal screening and targeted screening for a high-risk population. We used a societal perspective and assessed lifetime QALY gains. We derived outcomes from the literature and prospectively collected data. We performed one-way and probabilistic sensitivity analyses to assess parameter uncertainty.

Results: The incremental costs to society of universal and targeted screening programs compared to no screening were $\$ 2286.06 /$ QALY and \$1676.94/QALY, respectively. With a willingness-to-pay threshold of $\$ 50000 / \mathrm{Q} A \mathrm{~L}$, both programs were cost-effective. Compared to a targeted screening program, a universal screening program would cost an additional \$2965.96 to gain 1 QALY, which renders it a cost-effective option. The study findings were robust to extensive sensitivity analyses.

Interpretation: A proposed universal screening program for iron deficiency would be cost-effective over the lifespan compared to both no screening (current standard of care) and a targeted screening program for children at high risk. Policy-makers and physicians may consider expanding the recommended 18-month enhanced well-baby visit to include screening for iron deficiency.

T ron deficiency is the world's most prevalent micronutrient disorder, with a peak prevalence in children aged 6 months to 3 years. ${ }^{1}$ Early childhood is a sensitive period for neurodevelopment and overlaps with a period of rapid growth and transitions in feeding, which may result in inadequate daily iron intake. ${ }^{2}$ In developed countries, the prevalence of iron deficiency in young children is about $10 \%-15 \%$, and, in roughly 1 in 6 children, iron deficiency may progress to iron deficiency anemia, with a prevalence of about $2 \% .{ }^{3,4}$ Iron deficiency in infancy is associated with poor long-term neurocognitive and functional outcomes that may persist into adulthood. ${ }^{5-9}$ The current standard of care for children with iron deficiency anemia is diet advice and oral iron treatment for 3-6 months, which is effective in improving laboratory and developmental outcomes. ${ }^{10-12}$ Given the potential for nonanemic iron deficiency to progress to iron deficiency anemia, early detection and intervention may be beneficial. ${ }^{13}$

There is no current Canadian recommendation for screening for iron deficiency. The American Academy of Pediatrics recommends universal screening for anemia through mea- surement of hemoglobin at 12 months of age, but this approach has limitations, as the rapidly developing brain may be exposed to chronic iron deficiency by the time anemia is detected. ${ }^{2,14} \mathrm{We}$ recently assessed a strategy to screen for iron deficiency through measurement of serum ferritin at 18 months $;{ }^{15}$ however, the cost of this strategy has not been assessed. ${ }^{16}$ The purpose of the present study was to model the long-term cost-utility of a proposed iron deficiency screening program using measurement of serum ferritin in 18-monthold children during a scheduled health supervision visit in the general population and in a targeted high-risk population in Ontario.

Competing interests: See the end of the article.

This article has been peer reviewed.

Correspondence to: Sarah Carsley, sarah.carsley@oahpp.ca

CMAJ Open 2019. DOI:10.9778/cmajo.20190084 


\section{Methods}

\section{Target population}

The target population for this cost-utility analysis was children 18 months of age attending a scheduled 18-month health visit in a developed-country setting such as Canada.

\section{Model structure}

We used a decision tree model (Figure 1) to estimate the costs and quality-adjusted life years (QALYs) to obtain incremental cost-effectiveness ratios (ICERs) associated with 3 iron deficiency screening strategies: no screening, a universal screening program and a targeted screening program for a high-risk population (defined below). We selected the inputs of the decision tree model to reflect a general framework for evaluating the cost-effectiveness of screening programs. ${ }^{17} \mathrm{With}$ the understanding that iron deficiency during the sensitive period for neurodevelopment may lead to long-term poor functional outcomes, we chose a lifetime time horizon in our analysis. ${ }^{18,19}$
The model included health states at 4 terminal nodes: 1) "healthy, untreated" if iron deficiency was not present and treatment unnecessary, 2) "healthy, after treatment" if iron deficiency was detected and treated successfully, 3) "poor functional outcomes, after treatment" if iron deficiency was detected and treatment was unsuccessful and 4) "poor functional outcomes, untreated" if iron deficiency was not detected and not treated. The analysis was conducted from a societal perspective, wherein all costs irrespective of payer were included. We used an annual discounting rate of $1.5 \% .^{19}$ We followed guidelines for economic evaluations of newborn screening $^{20}$ and performed analyses using TreeAge Pro Software 18.2.1.

\section{Data sources}

We populated the model with data from the literature and prospectively collected data from our ongoing Optimizing Early Child Development (OptEC) study. ${ }^{13}$ This study is embedded in our pediatric primary care research network

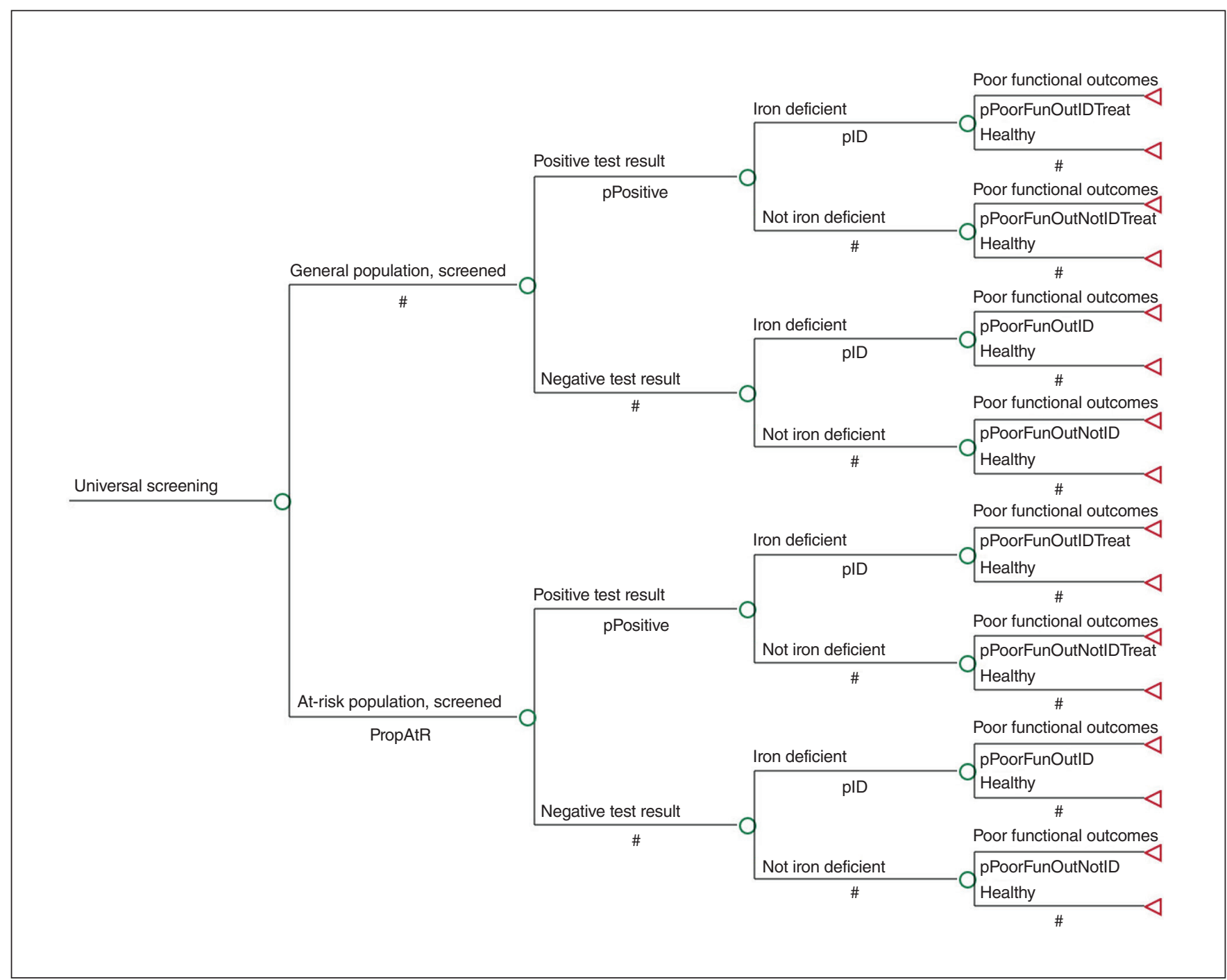

Figure 1: Decision tree model (universal screening branch only; full decision tree is available in Appendix 1, Supplemental Figure 1, available at www.cmajopen.ca/content/7/4/E689/suppl/DC1). 
called TARGet Kids! (www.targetkids.ca). ${ }^{3}$ The recruitment process for OptEC simulates our proposed iron deficiency screening program because blood is obtained from young children attending a scheduled health supervision visit in primary care. As of December 2018, about 1500 children had had questionnaire data and laboratory measures (including hemoglobin, serum ferritin and C-reactive protein) collected.

\section{Base-case model inputs}

\section{Prevalence of iron deficiency}

We derived a prevalence of iron deficiency in the general population of young children of $12 \%$ from a published review of 10 studies in Canadian children ${ }^{21}$ and from our contemporary urban OptEC cohort (Table 1). We defined children at high risk as those with 2 or more risk factors for iron deficiency (younger age [12-36 mo], longer breast-feeding duration, high body mass index z-score and drinking $>500 \mathrm{~mL}$ of cow's milk daily) (Table 1). ${ }^{26-34}$ Iron deficiency was defined as a serum ferritin level less than $12 \mu \mathrm{g} / \mathrm{L}^{2,35}$ in the base-case analysis and as a serum ferritin level less than $18 \mu \mathrm{g} / \mathrm{L}$ in the sensitivity analysis; the latter cut-off was derived from our recent analysis of data from the OptEC study (Appendix 1, Supplemental Table S1, available at www.cmajopen.ca/ content/7/4/E689/suppl/DC1). ${ }^{13}$

\section{Sensitivity and specificity of screening test}

Under both screening strategies, we proposed screening for iron deficiency by means of serum ferritin measurement, a commonly available test. Guyatt and colleagues ${ }^{22}$ analyzed data from 55 studies in adults that examined laboratory tests of iron status and histologic examination of bone marrow, and concluded that serum ferritin measurement is the most accurate test for the diagnosis of iron deficiency. As we did not identify any similar study in children, we used estimates from that study.

\section{Probability of poor functional outcomes}

We considered poor functional outcomes as a direct consequence of iron deficiency or due to causes other than iron

\begin{tabular}{|c|c|c|}
\hline Parameter & Base case & Data source/reasoning \\
\hline \multicolumn{3}{|l|}{ Prevalence of iron deficiency } \\
\hline General population & $12.1 \%$ & Hartfield $2010^{21}$ (review of 10 studies) \\
\hline At-risk population & $25.0 \%$ & $\begin{array}{l}\text { Optimizing Early Child Development study }{ }^{13} \text { data, Oatley } \\
\text { et al., } 2018^{15}(n=1735)\end{array}$ \\
\hline $\begin{array}{l}\text { Proportion of children at risk } \\
\text { in general population }\end{array}$ & $35.5 \%$ & $\begin{array}{l}\text { Optimizing Early Child Development study }{ }^{13} \text { data } \\
\left(\geq 2 \text { risk factors }{ }^{*}\right)\end{array}$ \\
\hline \multicolumn{3}{|c|}{ Probability of poor functional outcomes } \\
\hline \multicolumn{3}{|l|}{ Untreated } \\
\hline Due to iron deficiency & $23.5 \%$ & Lozoff et al., $2000^{6}$ (longitudinal cohort study, $n=167$ ) \\
\hline Not due to iron deficiency & $9.5 \%$ & $\begin{array}{l}\text { Idjradinata et al., } 1993^{12} \text { (randomized controlled trial } \\
\text { stratified by iron status; iron-deficiency anemia } n=50 \text {, } \\
\text { nonanemic iron deficiency } n=29 \text {, iron sufficiency } n= \\
\text { 47) }\end{array}$ \\
\hline \multicolumn{3}{|c|}{ After iron supplementation treatment } \\
\hline Due to iron deficiency & $9.5 \%$ & Idjradinata et al. ${ }^{12}$ \\
\hline Not due to iron deficiency & $9.5 \%$ & Idjradinata et al. ${ }^{12}$ \\
\hline \multicolumn{3}{|l|}{ Screening test efficiency } \\
\hline Sensitivity & $58.6 \%$ & Guyatt et al., $1992^{22}$ (review of 55 studies) \\
\hline Specificity & $98.9 \%$ & Guyatt et al. ${ }^{22}$ \\
\hline \multicolumn{3}{|l|}{ Utility parameter inputs } \\
\hline $\begin{array}{l}\text { Utility of having iron } \\
\text { supplementation treatment } \\
\text { (utilityTreat) }\end{array}$ & 0.815 & $\begin{array}{l}\text { Accounting for potential side effects (constipation) of } \\
\text { receiving iron supplementation, NICE } 2010^{23}\end{array}$ \\
\hline $\begin{array}{l}\text { Utility of living with poor } \\
\text { functional outcomes } \\
\text { (utilityPoorFunOut) }\end{array}$ & 0.84 & $\begin{array}{l}\text { Assuming children will experience utility loss owing to } \\
\text { cognitive impairment } \\
\text { Bennett et al., }{ }^{24} 2000 \text { (computer-based utility } \\
\text { assessment interview, } n=94 \text { ) } \\
\text { Ekman et al., }{ }^{25} 2007 \text { (cross-sectional study, } n=1800 \text { ) }\end{array}$ \\
\hline
\end{tabular}


deficiency. We also considered whether children with iron deficiency received oral iron treatment. The estimates used for our base case came from 2 published randomized controlled trials and a long-term observational study (Table 1). ${ }^{6,12,15}$ Untreated iron deficiency in infancy is associated with poor neurodevelopmental and functional outcomes. ${ }^{5,11,12,36}$ Lozoff and colleagues ${ }^{6}$ reported that, at 10 years of age, compared to children with good iron status in infancy, children with chronic, severe iron deficiency in infancy had higher rates of grade repetition $(26 \% \mathrm{v} .12 \%)$ and referral for special services $(21 \%$ v. $7 \%)$. We used the average of these rates as estimates of the probability of poor functional outcomes in children with untreated iron deficiency $(23.5 \%)$ and due to causes other than iron deficiency $(9.5 \%)$. These estimates were more conservative than those reported by Lozoff and colleagues ${ }^{9}$ in the same cohort at 25 years of age, when rates of incompletion of secondary school were compared (58\% v. 20\%).

To estimate the probability of poor functional outcomes in children with treated iron deficiency in infancy, we referred to data from the randomized trials of infants with iron deficiency anemia and nonanemic iron deficiency, which showed that mental development scores reversed in those who received 4 months of oral iron treatment but not in those who received placebo. ${ }^{11,12}$ Therefore, we used the same rate as for children with good iron status in the cohort followed by Lozoff and colleagues $^{6}(9.5 \%)$.

\section{Utility scores}

A QALY is calculated by multiplying the utility score by life expectancy (Table 2). We assumed that cognitive deficits beginning in infancy leading to poor functional outcomes in adulthood do not lead to early death; therefore, we assumed all children to have a life expectancy of 80.5 years at 18 months of age. ${ }^{37}$

We assigned a utility score of 1.0 to children who did not screen positive for iron deficiency and were assumed to have lifelong health. We assigned a utility score of 0.84 to children with poor functional outcomes, derived from the average of 2 sources by means of different instruments, to capture utilities across the life course (childhood to adulthood). First, a median utility of 0.87 was reported in a study of parents of children aged 3-36 months in which parents were presented with a scenario describing a child's illness and resulting poor functional outcomes such as problems with learning, problems with behavioural, attentional or social skills, and slightly lower intelligence. ${ }^{24}$ Second, a mean utility of 0.82 was reported in a study of healthy adults who were presented with vignettes and asked to imagine what it would be like to experience mild impairments in cognitive and functional performance. ${ }^{25}$

Treatment of iron deficiency with oral iron supplementation may be associated with minor gastrointestinal adverse events. ${ }^{10}$ Therefore, we assigned a utility score of 0.82 to a 4-month treatment period. ${ }^{23} \mathrm{We}$ did not consider disutility due to venipuncture, as a median utility of 1.0 has previously been identified. ${ }^{24}$

\section{Costs}

We considered both direct and indirect costs in our analysis (Table 3). We obtained the direct medical cost of the screening test from the Ontario Health Insurance Plan Laboratory Test Schedule of Benefits (effective April 2017) ${ }^{45}$ and adjusted it to present value (January 2019) using the Canadian Consumer Price Index. ${ }^{39}$ Although screening for iron deficiency may be based on serum ferritin measurement alone, to derive a conservative cost estimate, we included the additional cost for hemoglobin and C-reactive protein (C-reactive protein is recommended to exclude the possibility of acute inflammation). In the base-case analysis, we assumed an urban location for the specimen collection fee under both screening strategies. Alternative patient locations associated with different fees were assessed in sensitivity analyses. The unit price of targeted screening was $\$ 6.52$ more expensive than the universal strategy to account for increased clinician time to identify children at high risk. We estimated the direct 4-month treatment cost of a commonly

\section{Table 2: Calculation of effectiveness}

Terminal node health

state Formula

Healthy, untreated $\quad$ QALYs (healthy, untreat) $=$ RemainLifeExp*1 $=80.5$

Healthy, after

treatment

Poor functional

outcomes, untreated

QALYs (healthy, treat)
$+(0.33)^{\star}$ utilityTreat

QALYs (poor functional outcomes, untreat) = RemainLifeExp*utilityPoorFunOut

Poor functional

outcomes, after

treatment
QALYs (poor functional outcomes, treat) = (RemainLifeExp - 0.33)* utilityPoorFunOut $+(0.33)^{\star}$ utilityTreat
Reasoning

Assuming screening occurs at 18 months and health state is experienced for all years following test (using life expectancy of $82 \mathrm{yr}^{37}$ )

Assumes there is some decrease in utility for 4 mo during iron supplementation $(4 / 12 \mathrm{mo}=0.33)$

Assumes that iron deficiency is not detected and treated, and resulting health state is experienced for all years following test

Assumes that iron deficiency is not treated despite supplementation, and this health state experiences both decreased utilities from poor functional outcomes, and short-term decrease in utility due to supplementation

Note: $\mathrm{QALY}=$ quality-adjusted life year. 


\begin{tabular}{|c|c|c|}
\hline Parameter & Base case, $\$$ & Data source/reasoning \\
\hline \multicolumn{3}{|l|}{ Universal screening } \\
\hline \multicolumn{3}{|l|}{ Adjusted laboratory costs } \\
\hline Laboratory services & 10.67 & $\begin{array}{l}\text { OHIP Schedule of Benefits for Laboratory Services } \\
\text { (complete blood count, ferritin and C-reactive protein)* }\end{array}$ \\
\hline Administration & 6.37 & $\begin{array}{l}\text { Ontario Nurses Association (assuming 10-min nursing } \\
\text { time) } \dagger\end{array}$ \\
\hline $\begin{array}{l}\text { Patient documentation and } \\
\text { specimen collection fee }\end{array}$ & 10.76 & OHIP Schedule of Benefits (urban location) \\
\hline Total (uninflated) & $28.48(27.80)$ & $\begin{array}{l}\text { Inflated to value as of January } 2019 \text { using the monthly } \\
\text { Canadian Consumer Price Index } \neq\end{array}$ \\
\hline \multicolumn{3}{|l|}{ Patient-borne cost } \\
\hline Salary loss & 103.21 & $\begin{array}{l}\text { Average weekly wages for Canadians (permanent } \\
\text { employees) were } \$ 1032.12 \text { in January } 2019 .{ }^{40} \text { In the } \\
\text { base case, } 1 \text { parent is assumed to take } 0.5 \mathrm{~d} \text { off work. }\end{array}$ \\
\hline Travel expense & 13.12 & $\begin{array}{l}1 \text { parent driving conventional vehicle to screening } \\
\text { location ( } 15 \mathrm{~km} \text { round trip). Fuel consumption is } \\
7.8 \mathrm{~L} / 100 \mathrm{~km} \S \text { and cost of regular gasoline is } \$ 0.96 / \mathrm{L} \text {, } \emptyset \\
\text { for a total cost for gasoline of } \$ 1.12 \text {. In the base case, a } \\
\text { 1-hour parking time is assumed at } \$ 6 \text { per } 30 \mathrm{~min},{ }^{* *} \text { for a } \\
\text { parking cost of } \$ 12 \text {. }\end{array}$ \\
\hline Total & 116.33 & \\
\hline Total cost & 144.81 & \\
\hline \multicolumn{3}{|l|}{ Targeted screening } \\
\hline \multicolumn{3}{|l|}{ Adjusted laboratory costs } \\
\hline Laboratory services & 10.67 & As above \\
\hline Administration & 12.73 & As above \\
\hline $\begin{array}{l}\text { Patient documentation and } \\
\text { specimen collection fee }\end{array}$ & 10.76 & As above \\
\hline Total (uninflated) & $35.00(34.16)$ & $\begin{array}{l}\text { Inflated to value as of January } 2019 \text { using the monthly } \\
\text { Canadian Consumer Price Index } \neq\end{array}$ \\
\hline \multicolumn{3}{|l|}{ Patient-borne cost } \\
\hline Salary loss & 103.21 & As above \\
\hline Travel expense & 13.12 & As above \\
\hline Total & 116.33 & \\
\hline Total cost & 151.33 & \\
\hline $\begin{array}{l}\text { Treatment cost (ferrous } \\
\text { sulfate, } 4 \mathrm{mo} \text { ) }\end{array}$ & 170.00 & $\$ 168.63$ including dispensing fee ${ }^{44}$ \\
\hline \multicolumn{3}{|c|}{ 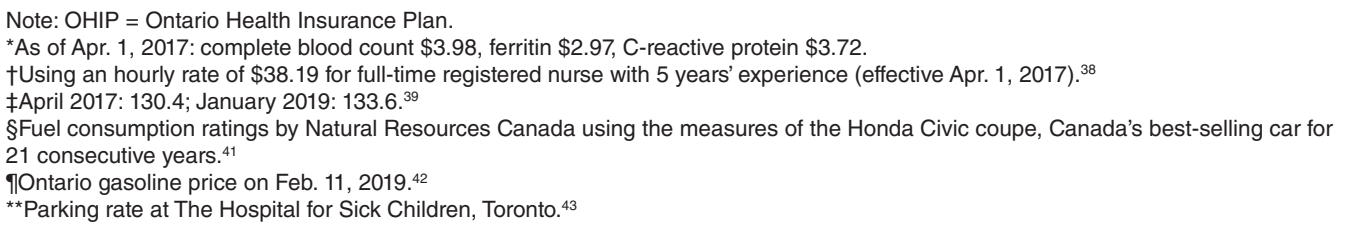 } \\
\hline
\end{tabular}

prescribed oral iron supplement (ferrous sulfate) from the Ontario Drug Benefit Formulary/Comparative Drug Index. ${ }^{44}$

We included the indirect (or time) cost paid by parents to attend a laboratory for phlebotomy. Estimation of salary loss was based on Statistics Canada labour statistics on the average weekly wage in January 2019 and 0.5 days off work. ${ }^{40}$ Parents were assumed to drive to the laboratory and park for 1 hour.
Arrival by public transportation and taking up to a full day off work were considered in sensitivity analyses. We did not include the cost of the 18-month visit, as this visit is currently recommended for all children and is covered by the Ontario Health Insurance Plan. To be conservative, we did not include direct or indirect lifetime costs of poor functional outcomes. 


\section{Sensitivity analysis}

We conducted extensive one-way sensitivity analyses to assess the uncertainty of the ICERs by varying the single-parameter values (Appendix 1, Supplemental Table S1). We performed probabilistic sensitivity analyses using 100000 Monte Carlo simulations to assess the simultaneous uncertainty around multiple variables (Appendix 1, Supplemental Table S2).

\section{Ethics approval}

Ethics approval was not required for this study. Ethics approval for the OptEC study was obtained from the research ethics boards at The Hospital for Sick Children and St. Michael's Hospital, Toronto.

\section{Results}

\section{Base case}

The marginal cost per child of each screening strategy was \$144.81 for universal, screen negative; \$314.81 for universal, screen positive; $\$ 151.33$ for targeted, screen negative; $\$ 321.33$ for targeted, screen positive; and $\$ 0.00$ for no screening.

In the base-case scenario, compared to no screening, a universal and a targeted screening program cost society an additional \$162.98 and \$63.06, respectively, in exchange for 0.07 and 0.04 QALY gains, respectively, in a lifetime (Table 4, Appendix 1, Supplemental Figure 2). The ICERs for the universal and the targeted screening programs relative to no screening were \$2286.06/QALY and \$1676.94/QALY, respectively. With 2 common willingness-to-pay thresholds of $\$ 50000$ and $\$ 100000$ per QALY, ${ }^{46}$ both screening strategies were cost-effective over no screening. The universal program was $\$ 99.92$ more expensive than the targeted program while producing 0.03 additional QALYs in a lifetime, giving an ICER of \$2965.96/QALY. Therefore, the universal screening program is cost-effective compared to the targeted program.

\section{Sensitivity analyses}

\section{One-way sensitivity analyses}

Figure 2 shows the tornado diagrams of the one-way sensitivity analyses. The base-case conclusions were robust to all single-parameter variations. When the probability of irondeficiency-associated poor functional outcomes was as low as $8.4 \%$, the ICERs of universal and targeted screening programs reached \$11 679.36/QALY and \$8888.30/QALY, respectively, compared to no screening, and the ICER of the universal program reached \$14 565.99/QALY compared to targeted screening, still far below the threshold of $\$ 50$ 000/ QALY.

\section{Probabilistic sensitivity analyses}

Probabilistic sensitivity analyses showed that, 98.8\% and $99.0 \%$ of the time, the ICER for universal screening or targeted screening as compared to no screening would be below the threshold of $\$ 50000$ (Figure 3). When universal screening was compared to targeted screening, the former was cost-effective $98.5 \%$ of the time.

\section{Interpretation}

Our findings suggest that a universal screening program for iron deficiency is cost-effective compared to the current practice of no screening or a targeted screening program for children at high risk. These results were robust to extensive sensitivity analyses. In our analysis, we chose parameters that would result in conservative estimates of cost-effectiveness. These included assuming that no further costs would be incurred owing to poor functional outcomes, as there may be direct costs or indirect costs, or both, associated with public or private assessments and interventions for people with developmental difficulties, at any time from childhood to adulthood. We assumed no additional societal costs owing to lower school completion or early death, and included a cost for parents' taking time off work for an additional laboratory visit. The diagnostic accuracy of the screening test was based on serum ferritin measurement alone despite including the cost of a complete blood count, which would improve the sensitivity and specificity of iron deficiency detection, thereby increasing cost-effectiveness. In our model, once the present value of the lifetime cost associated with poor functional outcomes exceeded $\$ 12$ 000, both screening programs would be cost-saving compared to no screening.

\begin{tabular}{|c|c|c|c|c|c|}
\hline Strategy & Cost, $\$$ & Effect, QALYs & $\begin{array}{l}\text { Incremental } \\
\text { cost }\end{array}$ & $\begin{array}{c}\text { Incremental effect, } \\
\text { QALYs }\end{array}$ & ICER \\
\hline \multicolumn{6}{|c|}{2 screening programs v. no screening } \\
\hline No screening & 0.00 & 23.82 & - & - & - \\
\hline Targeted screening & 63.06 & 23.86 & 63.06 & 0.04 & 1676.94 \\
\hline Universal screening & 162.98 & 23.89 & 162.98 & 0.07 & 2286.06 \\
\hline \multicolumn{6}{|c|}{ Universal screening v. targeted screening } \\
\hline Targeted screening & 63.06 & 23.86 & - & - & - \\
\hline Universal screening & 162.98 & 23.89 & 99.92 & 0.03 & 2965.96 \\
\hline
\end{tabular}


A

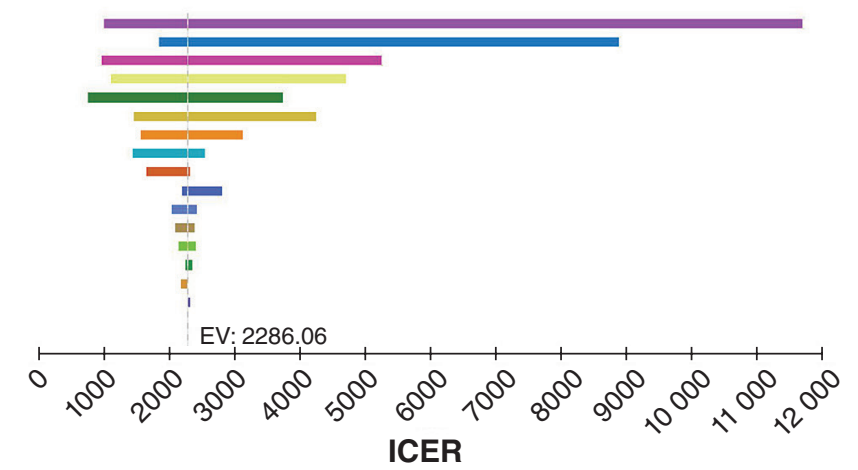

C

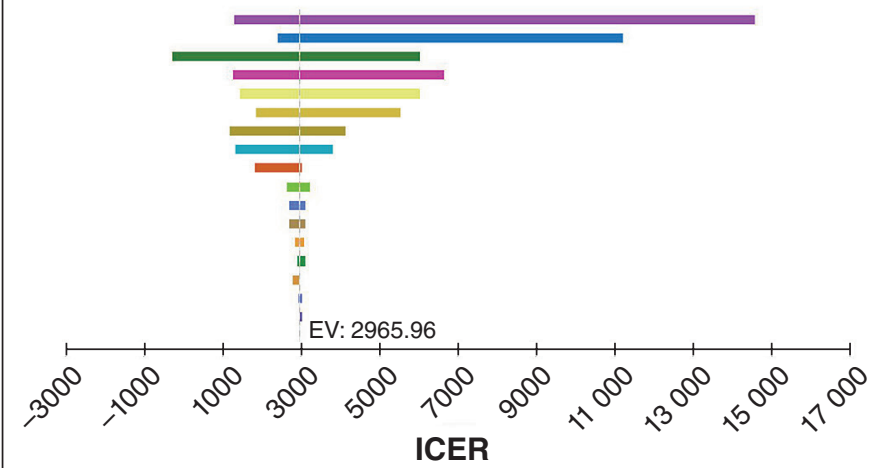

B

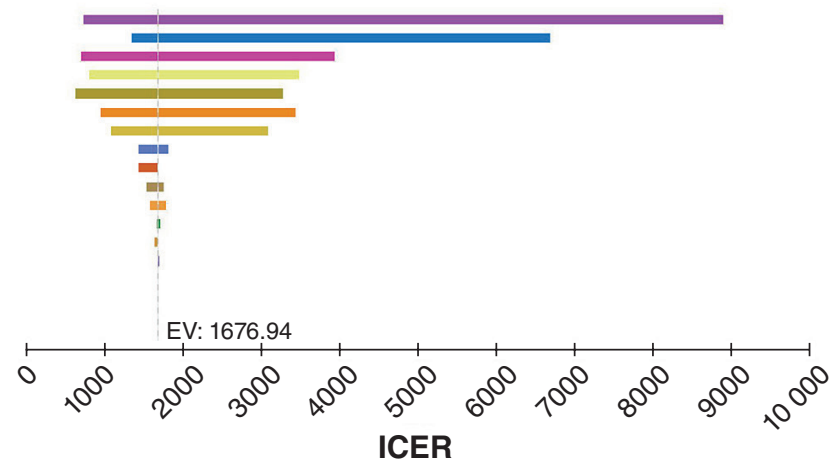

Figure 2: One-way sensitivity analyses comparing (A) universal screening versus no screening, (B) targeted screening versus no screening and (C) universal screening versus targeted screening. Note: EV = expected value (equivalent to the base-case incremental cost-effectiveness ratio [ICER]), ID = iron deficiency, prob = probability.

Our results suggest that the costs saved by restricting the program to children at high risk would be offset by the loss of QALYs for unscreened children at average risk. This is likely driven by the small incremental cost difference between the universal program and the targeted program (\$99.92). Hence, an additional $\$ 100$ spent in a universal program would be exchanged for $\$ 1500$ worth of effectiveness ( 0.03 extra QALYs $\times \$ 50000 / \mathrm{QALY}=\$ 1500$ ), which is highly cost-effective.

We identified 1 published economic analysis of anemia prevention, by Shaker and colleagues, ${ }^{47}$ in infants aged 9-12 months in the United States, where anemia screening (with hemoglobin) is currently recommended. They concluded that screening by means of an alternative test called reticulocyte hemoglobin content was an affordable strategy compared to hemoglobin alone. Their analysis differed from ours in several ways. Shaker and colleagues ${ }^{47}$ did not include a no-screening strategy, used reticulocyte hemoglobin content (rather than serum ferritin, which is more widely available and well known to physicians ${ }^{2}$ ) and proposed screening at 9-12 months. We selected the 18-month visit, as our previous analysis showed that the serum ferritin level is lowest between
15 and 24 months and that the hemoglobin level does not change substantially between 12 and 24 months. ${ }^{15}$ Finally, Shaker and colleagues ${ }^{47}$ included the cost of use of additional health care services for children with untreated iron deficiency, whereas we did not.

In keeping with the World Health Organization principles, ${ }^{48}$ the goal of screening for iron deficiency is early detection and treatment before progression to chronic, severe iron deficiency or iron deficiency anemia. A Cochrane systematic review identified 8 trials of iron treatment in young children with iron deficiency anemia; however, only 1 study used a duration of treatment $(4 \mathrm{mo})$ consistent with the current standard of care. ${ }^{36}$ That randomized trial showed that developmental scores were reduced in the infants with iron deficiency anemia before treatment and reversed after iron treatment, with follow-up scores similar to those for healthy children with iron sufficiency. ${ }^{12}$ Another randomized trial in infants with nonanemic iron deficiency similarly showed that developmental scores were reduced before treatment and improved after treatment. ${ }^{11}$ Lozoff and colleagues ${ }^{5-9}$ followed a cohort of Costa Rican children to 25 years of age and found that 


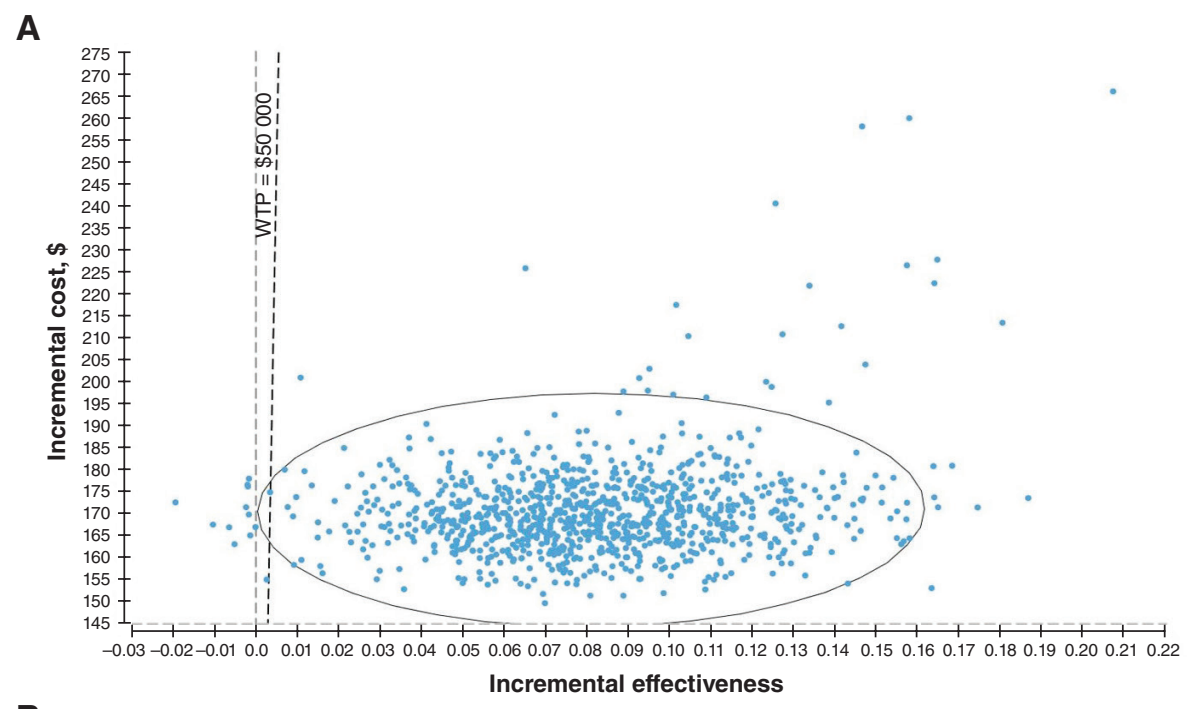

B

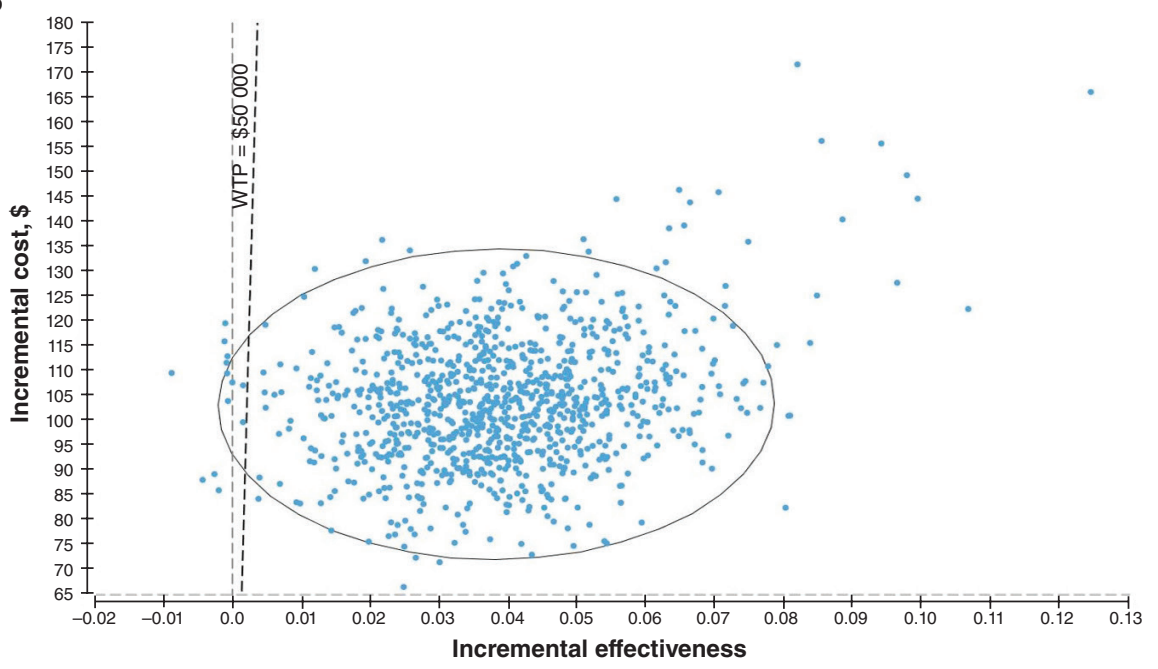

C

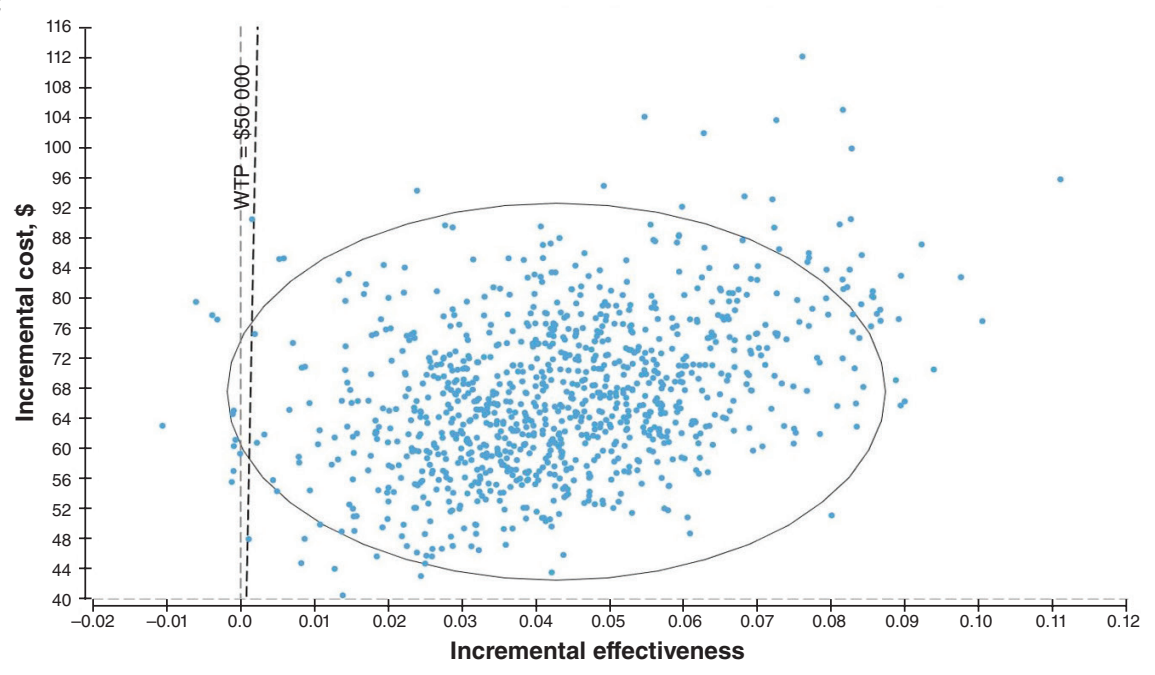

Figure 3: Probabilistic sensitivity analyses results comparing $(A)$ universal screening versus no screening, (B) targeted screening versus no screening and $(C)$ universal screening versus targeted screening. Note: WTP = willingness to pay. 
those with chronic, severe iron deficiency in infancy had poorer long-term cognitive and functional outcomes than those who were iron sufficient in infancy (before or after iron therapy). Together, these studies suggest that early detection of iron deficiency followed by a good response to oral iron treatment may lead to more favourable outcomes and that late detection of iron deficiency may be accompanied by slow response to oral iron treatment and poor long-term outcomes.

The Canadian Paediatric Society and the College of Family Physicians of Canada recommend an 18-month enhanced well-baby visit in primary care, which has been implemented in Ontario with a physician fee incentive. ${ }^{49,50}$ This may be an ideal visit for screening for iron deficiency, is aligned with the goal of improving child developmental outcomes, and is feasible owing to the high uptake of this visit for vaccinations and health surveillance. ${ }^{51}$

Strong recommendations have been made for investment in early childhood, considering the evidence supporting the developmental origins of health and disease. Heckman developed the "Heckman equation," which describes a high return on investment for preventive initiatives early in the life course. ${ }^{52-54}$ In keeping with this theory, screening and treatment for iron deficiency in early childhood has the potential to improve outcomes throughout the life course, with a modest economic investment.

Opportunities for future research include understanding the values and preferences of parents and practitioners for screening for iron deficiency; conducting a budget impact analysis to assess system-level costs associated with screening; developing a risk-stratification tool to be used for targeted screening (similar to tools for assessing risk of diabetes in adults); $; 5$ and validating a point-of-care tool for serum ferritin to improve convenience and reduce cost. ${ }^{16,56}$

\section{Limitations}

Our analysis has limitations common in cost-effectiveness analyses..$^{57,58}$ First, we could not identify any sources to estimate the accuracy of serum ferritin measurement in children (and therefore used data from adults) and iron-deficiencyspecific utility scores (and therefore used data from similar scenarios). Sources to estimate the probability of poor functional outcomes were methodologically strong and included randomized controlled trials and a long-term observational study; however, these studies were conducted in developing countries. Second, we did not include future costs that might be incurred as a result of poor functional outcomes, which led to a conservative estimate of costs. However, the inclusion of these costs in our model would increase the cost-effectiveness of the 2 screening programs compared to no screening.

\section{Conclusion}

A proposed universal screening program for iron deficiency would be cost-effective over the lifespan compared to both no screening (current standard of care) and a targeted screening program for children at high risk. Policy-makers and physicians may consider expanding the recommended 18 -month enhanced well-baby visit to include screening for iron deficiency.

\section{References}

1. Iron deficiency anemia assessment, prevention and control: a guide for programme managers. Geneva: World Health Organization; 2001. Available: http://whqlibdoc.who.int/hq/2001/WHO_NHD_01.3.pdf (accessed 2018 Nov. 30).

2. Baker RD, Greer FR; Committee on Nutrition American Academy of Pediatrics. Diagnosis and prevention of iron deficiency and iron-deficiency anemia in infants and young children (0-3 years of age). Pediatrics 2010;126:1040-50.

3. Carsley S, Borkhoff CM, Maguire JL, et al.; TARGet Kids! Collaboration. Cohort profile: The Applied Research Group for Kids (TARGet Kids!). Int 7 Epidemiol 2015;44:776-88.

4. Gupta PM, Hamner HC, Suchdev PS, et al. Iron status of toddlers, nonpregnant females, and pregnant females in the United States. Am 7 Clin Nutr 2017; 106(Suppl 6):1640S-6S.

5. Lozoff B, Brittenham GM, Wolf AW, et al. Iron deficiency anemia and iron therapy effects on infant developmental test performance [erratum in Pediatrics 1988;81:683]. Pediatrics 1987;79:981-95.

6. Lozoff B, Jimenez E, Hagen J, et al. Poorer behavioral and developmental outcome more than 10 years after treatment for iron deficiency in infancy. Pediatrics 2000;105:E51.

7. Lozoff B, Jimenez E, Smith JB. Double burden of iron deficiency in infancy and low socioeconomic status: a longitudinal analysis of cognitive test scores to age 19 years. Arch Pediatr Adolesc Med 2006;160:1108-13.

8. Lozoff B, Jimenez E, Wolf AW. Long-term developmental outcome of infants with iron deficiency. N Engl f Med 1991;325:687-94.

9. Lozoff B, Smith JB, Kaciroti N, et al. Functional significance of early-life iron deficiency: outcomes at 25 years. 7 Pediatr 2013;163:1260-6.

10. Powers JM, Buchanan GR, Adix L, et al. Effect of low-dose ferrous sulfate vs iron polysaccharide complex on hemoglobin concentration in young children with nutritional iron-deficiency anemia: a randomized clinical trial. $7 A M A$ 2017;317:2297-304.

11. Akman M, Cebeci D, Okur V, et al. The effects of iron deficiency on infants' developmental test performance. Acta Paediatr 2004;93:1391-6.

12. Idjradinata P, Pollitt E. Reversal of developmental delays in iron-deficient anaemic infants treated with iron. Lancet 1993;341:1-4.

13. Abdullah K, Thorpe KE, Mamak E, et al. Optimizing early child development for young children with non-anemic iron deficiency in the primary care practice setting $(\mathrm{OptEC})$ : study protocol for a randomized controlled trial. Trials 2015;16:132.

14. Georgieff MK. Iron assessment to protect the developing brain. Am 7 Clin Nutr 2017;106(Suppl 6):1588S-93S.

15. Oatley H, Borkhoff CM, Chen S, et al. Screening for iron deficiency in early childhood using serum ferritin in the primary care setting. Pediatrics 2018; 142: e20182095.

16. Cohen AR. Looking behind the iron curtain. Pediatrics 2018;142:e20183068.

17. Flaherman VJ, Porco TC, Marseille E, et al. Cost-effectiveness of alternative strategies for tuberculosis screening before kindergarten entry. Pediatrics 2007; 120:90-9.

18. Basu A, Maciejewski ML. Choosing a time horizon in cost and cost-effectiveness analyses. FAMA 2019;321:1096-7.

19. Guidelines for the economic evaluation of health technologies: Canada. 4th ed. Ottawa: Canadian Agency for Drugs and Technologies in Health; 2017. Available: www.cadth.ca/sites/default/files/pdf/guidelines_for_the_economic evaluation_of_health_technologies_canada_4th_ed.pdf (accessed 2019 Feb. 11).

20. Langer A, Holle R, John J. Specific guidelines for assessing and improving the methodological quality of economic evaluations of newborn screening. BMC Health Serv Res 2012;12:300.

21. Hartfield D. Iron deficiency is a public health problem in Canadian infants and children. Paediatr Child Health 2010;15:347-50.

22. Guyatt GH, Oxman $\mathrm{AD}$, Ali M, et al. Laboratory diagnosis of iron-deficiency anemia: an overview. 7 Gen Intern Med 1992;7:145-53.

23. National Collaborating Centre for Women's and Children's Health (UK). Constipation in children and young people: diagnosis and management of idiopathic childhood constipation in primary and secondary care. London (UK): RCOG Press; 2010.

24. Bennett JE, Sumner W 2nd, Downs SM, et al. Parents' utilities for outcomes of occult bacteremia. Arch Pediatr Adolesc Med 2000;154:43-8.

25. Ekman M, Berg J, Wimo A, et al. Health utilities in mild cognitive impairment and dementia: a population study in Sweden. Int 7 Geriatr Psychiatry 2007;22: 649-55.

26. Abdullah K, Thorpe KE, Maguire JL, et al. Risk factors, practice variation and hematological outcomes of children identified with non-anemic iron deficiency following screening in primary care setting. Paediatr Child Health 2015;20: 302-6.

27. Bayoumi I, Parkin PC, Lebovic G, et al. Iron deficiency among low income Canadian toddlers: a cross-sectional feasibility study in a Community Health Centre and non-Community Health Centre sites. BMC Fam Pract 2018;19: 161.

28. Cox KA, Parkin PC, Anderson LN, et al.; TARGet Kids! Collaboration. Association between meat and meat-alternative consumption and iron stores in early childhood. Acad Pediatr 2016;16:783-91. 
29. Maguire JL, Lebovic G, Kandasamy S, et al.; TARGet Kids! Collaboration. The relationship between cow's milk and stores of vitamin D and iron in early childhood. Pediatrics 2013;131:e144-51.

30. Maguire JL, Salehi L, Birken CS, et al.; TARGet Kids! Collaboration. Association between total duration of breastfeeding and iron deficiency. Pediatrics 2013;131:e1530-7.

31. Parkin PC, DeGroot J, Maguire JL, et al. Severe iron-deficiency anaemia and feeding practices in young children. Public Health Nutr 2016;19:716-22.

32. Saunders NR, Parkin PC, Birken CS, et al.; TARGet Kids! Collaboration. Iron status of young children from immigrant families. Arch Dis Child 2016;101: 1130-6.

33. Sutcliffe TL, Khambalia A, Westergard S, et al. Iron depletion is associated with daytime bottle-feeding in the second and third years of life. Arch Pediatr Adolesc Med 2006;160:1114-20.

34. Sypes EE, Parkin PC, Birken CS, et al.; TARGet Kids! Collaboration. Higher body mass index is associated with iron deficiency in children 1 to 3 years of age. F Pediatr 2019;207:198-204.e1.

35. Assessing the iron status of populations: including literature reviews - report of a foint World Health Organization/Centers for Disease Control and Prevention Technical Consultation on the Assessment of Iron Status at the Population Level, Geneva, Switzerland, 6-8 April 2004. 2nd ed. Geneva: World Health Organization; 2007.

36. Wang B, Zhan S, Gong T, et al. Iron therapy for improving psychomotor development and cognitive function in children under the age of three with iron deficiency anaemia. Cochrane Database Syst Rev 2013;(6):CD001444.

37. Life tables, Canada, provinces and territories. Cat no 84-537-X. Ottawa: Statistics Canada. Available: www150.statcan.gc.ca/n1/pub/84-537-x/2018002/ xls/2014-2016_Tbl-eng.xlsx (accessed 2019 May 6).

38. Highlights of collective agreement changes as a result of the Albertyn Award and items in agreement between ONA and participating hospitals. Term: April 1, 2016 to March 31, 2018. Toronto: Ontario Nurses Association; 2016. Available: www.ona.org/wp-content/uploads/ona_2016hospitalawardhighlights_ 20160912.pdf?x72008 (accessed 2019 Mar. 6).

39. Table 18-10-0004-13: Consumer Price Index by product group, monthly, percentage change, not seasonally adjusted, Canada, provinces, Whitehorse, Yellowknife and Iqaluit. Ottawa: Statistics Canada; modified 2019 Oct. 29. Available: www150.statcan.gc.ca/t1/tbl1/en/tv.action? pid=1810000413 (accessed 2019 Feb. 11).

40. Table 14-10-0320-02: Average usual hours and wages by selected characteristics, monthly, unadjusted for seasonality. Ottawa: Statistics Canada; modified 2019 Oct. 29. Available: www150.statcan.gc.ca/t1/tbl1/en/tv.action?pid= 1410032002\&pickMembers\%5B0\%5D=3.3 (accessed 2019 Feb. 11).

41. Fuel consumption ratings search tool. Ottawa: Natural Resources Canada. Available: https://fcr-ccc.nrcan-rncan.gc.ca/en (accessed 2019 Mar. 6).

42. Motor fuel prices. Government of Ontario. Available: www.ontario.ca/page/ motor-fuel-prices (accessed 2019 Feb. 11).

43. SickKids Hospital parking. Precise ParkLink Inc. Available: www. findparkingnearme.ca/sickkids-toronto (accessed 2019 Mar. 6).

44. Ontario Ministry of Health and Long-Term Care. Ontario Drug Benefit Formulary/Comparative Drug Index. Toronto: Queen's Printer for Ontario; updated 2018 Nov. 8. Available: www.formulary.health.gov.on.ca/formulary/ (accessed 2019 Feb. 11).

45. Schedule of benefits for laboratory services, November 7, 2017 (effective April 1, 2017). Toronto: Ministry of Health and Long-Term Care; 2018. Available: www. health.gov.on.ca/en/pro/programs/ohip/sob/lab/lab_mn2018.pdf (accessed 2019 Feb. 11).

46. Neumann PJ, Cohen JT, Weinstein MC. Updating cost-effectiveness - the curious resilience of the \$50,000-per-QALY threshold. N Engl 7 Med 2014;371:796-7.

47. Shaker M, Jenkins P, Ullrich C, et al. An economic analysis of anemia prevention during infancy. 7 Pediatr 2009;154:44-9.

48. Wilson JMG, Jungner G. Principles and practice of screening for disease. Geneva: World Health Organization; 1968.

49. Williams R, Clinton J; Canadian Paediatric Society, Early Years Task Force. Getting it right at 18 months: in support of an enhanced well-baby visit. Paediatr Child Health 2011;16:647-54.

50. Your child's enhanced 18-month well-baby visit. Toronto: Ontario Ministry of Children, Community and Social Services; modified 2017 Apr. 24. Available: www.children.gov.on.ca/htdocs/English/earlychildhood/health/your_enhanced_ 18-month.aspx (accessed 2019 Feb. 6).

51. Ontario Agency for Health Protection and Promotion (Public Health Ontario). Immunization coverage report for school pupils: 2013-14, 2014-15 and 2015-16 school years. Toronto: Queen's Printer for Ontario; 2017. Available: www. publichealthontario.ca/-/media/documents/immunization-coverage-2013-16.pdf? la=en (accessed 2019 Sept. 12).
52. Conti G, Heckman JJ. The economics of child well-being. In: Ben-Arieh A, Casas F, Frønes I, et al., editors. Handbook of child well-being: theories, methods and policies in global perspective. Berlin: Springer; 2014:363-401.

53. Conti G, Heckman JJ. The developmental approach to child and adult health. Pediatrics 2013;131(Suppl 2):S133-41.

54. Heckman JJ. The developmental origins of health. Health Econ 2012;21:24-9.

55. Pottie K, Jaramillo A, Lewin G, et al.; Canadian Task Force on Preventive Health Care. Recommendations on screening for type 2 diabetes in adults. CMA7 2012;184:1687-96.

56. Srinivasan B, O'Dell D, Finkelstein JL, et al. ironPhone: mobile devicecoupled point-of-care diagnostics for assessment of iron status by quantification of serum ferritin. Biosens Bioelectron 2018;99:115-21.

57. Sanders GD, Maciejewski ML, Basu A. Overview of cost-effectiveness analysis. 7AMA 2019;321:1400-1.

58. Sanders GD, Neumann PJ, Basu A, et al. Recommendations for conduct, methodological practices, and reporting of cost-effectiveness analyses: second panel on cost-effectiveness in health and medicine. FAMA 2016;316:1093-103.

Competing interests: Patricia Parkin reports a grant from the Canadian Institutes of Health Research (FRN 115059) for an ongoing investigatorinitiated trial of iron deficiency in young children, for which Mead Johnson Nutrition provided nonfinancial support (2011-2017), related to this study. She reports peer-reviewed grants for completed investigatorinitiated studies from the Danone Institute of Canada (2002-2004 and 2006-2009) and Dairy Farmers of Ontario (2008-2010), unrelated to this study. Eva Baginska is the current director of Health Economics and Outcomes Research at BD-Canada. No other competing interests were declared.

Affiliations: Health Promotion, Chronic Disease and Injury Prevention (Carsley), Public Health Ontario; Institute of Health Policy, Management and Evaluation (Fu, Borkhoff, Reid, Baginska, Birken, Maguire, Hancock-Howard, Parkin, Coyte), Dalla Lana School of Public Health, University of Toronto; Child Health Evaluative Sciences (Borkhoff, Birken, Parkin), Peter Gilgan Centre for Research and Learning, The Hospital for Sick Children; Division of Pediatric Medicine and the Pediatric Outcomes Research Team (Borkhoff, Birken, Maguire, Parkin), Department of Pediatrics, Faculty of Medicine, University of Toronto, The Hospital for Sick Children; Department of Pediatrics (Maguire), St. Michael's Hospital and Li Ka Shing Knowledge Institute; Department of Nutritional Sciences (Birken, Maguire), University of Toronto, Toronto, Ont.

Contributors: Sarah Carsley and Rui Fu contributed equally as co-first authors. Patricia Parkin and Peter Coyte contributed equally as co-senior authors. Sarah Carsley, Patricia Parkin, Nadine Reid and Eva Baginska conceived and designed the study. Rui Fu analyzed the data. Rui Fu, Sarah Carsley and Patricia Parkin drafted the manuscript. Cornelia Borkhoff, Nadine Reid, Eva Baginska, Catherine Birken, Jonathon Maguire, Rebecca Hancock-Howard and Peter Coyte contributed to the study design and data interpretation. Cornelia Borkhoff, Catherine Birken and Jonathon Maguire provided data. All of the authors reviewed the manuscript critically for important intellectual content, approved the final version to be published and agreed to be accountable for all aspects of the work.

Funding: The Optimizing Early Child Development study is supported by grant FRN 115059 from the Canadian Institutes of Health Research. The Pediatric Outcomes Research Team is supported by a grant from The Hospital for Sick Children Foundation.

Disclaimer: The funding agencies and BD-Canada had no role in the design, collection, analyses or interpretation of the results of this study or in the preparation, review or approval of the manuscript.

Supplemental information: For reviewer comments and the original submission of this manuscript, please see www.cmajopen.ca/content/7/4/ E689/suppl/DC1. 